\title{
THE ENZYMATIC TRANSFORMATION OF URIDINE DIPHOSPHATE GLUCOSE INTO A GALACTOSE DERIVATIVE
}

\author{
LUIS F. LELOIR \\ Instituto de Investigaciones Bioquimicas, Fundación Campomar \\ Julián Alvarez 1719, Buenos Aires, Argentina \\ Received May 14, 1951
}

\section{INTRODUCTION}

A previous paper ${ }^{1}$ reported the isolation of a substance acting as coenzyme in the transformation of galactose phosphate into glucose phosphate. The structure of this coenzyme (UDPG) ${ }^{1}$ can be described as a glucose 1 : phosphate molecule attached to uridine 5'phosphate forming a pyrophosphate link.

In view of the fact that hexose phosphate is the substrate and also a part of the coenzyme, investigations were carried out in order to detect possible changes brought about by the enzyme on the sugar moiety of the coenzyme. The enzyme used was an extract of Saccharomyces fragilis, which can transform galactose 1-phosphate into glucose 1-phosphate in the presence of UDPG. It was found that when UDPG alone is incubated with this enzyme preparation a part of the glucose is transformed into galactose. As shown in Fig. 1 , the reaction reaches an equilibrium in which about $25 \%$ of the sugar is galactose and the rest-glucose. Detection of galactose was carried out by paper chromatography with the pyridine-ethyl acetate solvent described by Jermyn and Isherwood ${ }^{2}$. Considerable experience with this procedure has shown that galactose can be distinguished from 20 other sugars or related compounds.

Other procedures such as selective fermentation or colored reactions while giving approximately the expected results were not convincing.

After it was found that a galactose-contain-

1 The following abbvreviations are used: UDPG = uridine diphosphate glucose; $\mathrm{UDPGa}=$ uridine diphosphate galactose; glu-1-P = glucose 1-phosphawe; gal-1-P = galactose 1-phosphate; UMP = uridine 5'-phosphate. ing compound was formed by enzyme action on UDPG, information was sought on the identity of this compound. The most obvious possibilities were UDPGa, gal-1-P, or free gagalactose. Three types of experiments were carried out in order to settle this point.

(a) The nucleotides can be precipitated with mercuric salts leaving the esters and free sugars in the supernatant. The galactose-containing compound was found to precipitate with mercury like UDPG.

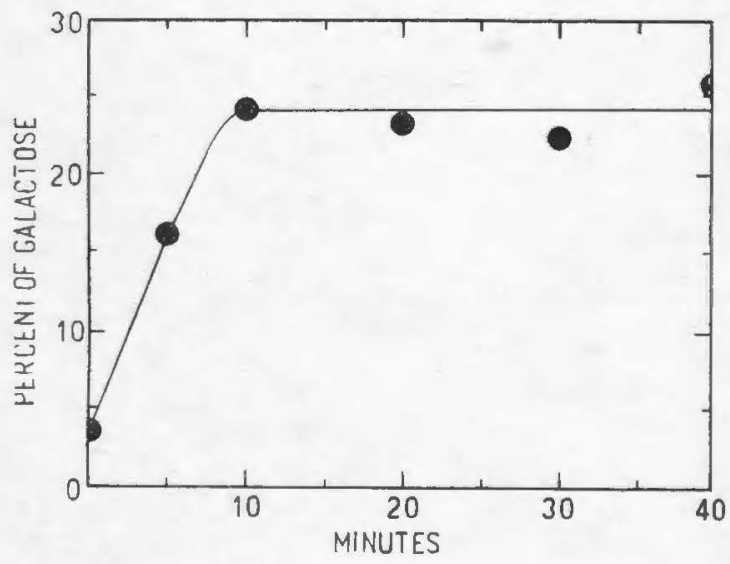

FIr. 1. - Formation of galactose by incubation of UDPG with $S$. fragilis extract. Incubation at $37^{\circ}$ of $2 \mu$ moles of UDPG with $0.04 \mathrm{ml}$. of dialyzed $S$. friagilis extract. After incubation $0.02 \mathrm{ml}$. of $2 \mathrm{~N} \mathrm{H}_{2} \mathrm{SO}_{4}$ was added, the tubes were heated $15 \mathrm{~min}$. at $100^{\circ}$ and cooled. Three-tenths $\mathrm{ml}$. of $0.3 \mathrm{M}$ barium hydroxide was added and then $0.1 \mathrm{ml}$. of $5 \%$ zinc sulfate. After centrifuging, the samples were evaporated and deposited on filter paper for chromatography (see text). Ordinates represent the per cent of galactose in total hexose.

(b) UDPG can be separated from the esters and free sugar by chromatography with ethanol-acetate at $\mathrm{pH}$ 3.8. Here the galactose compound was found in the UDPG zone. 
(c) It has been found ${ }^{3}$ that when UDPG is chromatographed with ethanol-ammonia the compound breaks down to uridylic acid and a compound containing one glucose molecule and one phosphate which is doubly esterified. This compound will be referred to as the cyclic phosphate. This compound migrates in the solvent much faster than any of the known hexose monophosphates and slightly slower than free hexoses. In this type of chromatography it was found that the cyclic phosphate zone contained both glucose and galactose.

Therefore, all the experiments agree in that incubation of UDPG with the $S$. fragilis extract gives rise to a new compound in which the glucose is replaced by galactose. This compound may be referred to as UDPGa.

In order to correlate this enzymatic change with the catalytic role of UDPG in the transformation of galactose 1-phosphate into glucose 1-phosphate this reaction can be separated into two steps:

$$
\begin{gathered}
\text { UDPG }+ \text { gal-1-P } \rightleftharpoons \text { UDPGa }+ \text { glu-1-P } \\
\text { UDPGa } \rightleftharpoons \text { UDPG. }
\end{gathered}
$$

Reaction 1, which is hypothetical, is a transfer of UMP from glucose phosphate to galactose phosphate, while reaction 2 is proved to occur by the experiments reported in this paper.

As to the mechanism of reaction 2 , one possibility would be an aldolase type of splitting between C-3 and C-4 of the hexose followed by recombination. This would necessitate the formation of free triose. Experiments designed to detect triose in the reaction mixture either with or without a trapping agent such as cyanide have been negative.

In connection with the cyclic phosphate formed by the action of ammonia on UDPG it may be mentioned that Forrest and Todd ${ }^{4}$ have independently found that flavine adenine dinucleotide suffers a similar degradation which leads to the formation of a ribityl flavine monophosphate, which is doubly esterified at positions 4 and 5 . The degradation product of UDPG is nonreducing, and therefore one point of attachment of the phosphate is at position 1 . The other point of at- tachment had not been established. For an a-glucose derivative it might conceivably be cither 1,2 or 1,4 . Since UDPGa also gives rise to the diester and on steric grounds it would be highly improbable to have a 1,4-galactose compound, it seems reasonable to suppose that the substances in question are esterified at positions 1 and 2 .

\section{EXPERIMENTAL}

The substrates and $S$. fragilis extract were prepared as deseribed previously (1). For most experiments the enzyme preparation was dialyzed $6 \mathrm{hr}$. in the cold. The separation of galactose from glucose wis carricd out by descending paper chromatography using a pyridine-ethyl acetate-water $(5: 10: 6)$ solvent (2) equilibrated at $30^{\circ}$ before separation of the two phases.

The samples were deposited as a band on $2 \mathrm{~cm}$. wide Whatman No. 1 filter-paper strips which had a blotting paper pad stapled on the end (5). Xylose was added in all the experiments as an internal standard. After running for 16-20 hr. the papers were dried, immermed in butanol-aniline-phthalate reagent (6) and the color was developed by heating to $105^{\circ}$ for $5 \mathrm{~min}$. With this reagent free hexoses give a brown color immediately; the l-esters, UDPG, and the cyclic phosphates give faint colors and only after prolonged heating. For some experiments (Fig. 1), the spots were cut out, extracted overnight with $3.5 \mathrm{ml}$, of $0.7 \mathrm{~N} \mathrm{HCl}$ in $80 \%$ ethanol at room temperature and the optical density was measured with a Beckman spectrophotometer at $400 \mathrm{~m} \mu$. If appropiate glucose and galactose standards were run at the same time the results were satisfacory from the quantitative point of view.

\section{(a) Precipitation of the Galactose Compound with Mercuric Acetate}

Six micromoles of UDPG in $0.2 \mathrm{ml}$. of water was incubated with $0.05 \mathrm{ml}$. of $S$. fragilis extract for 15 min. at $37^{\circ}$. The control contained the same components but the enzymatic reaction was stopped lat 0 -time, and $2 \mu$ moles of galactose 1 -phosphate and of galactose were added. These addition were made in order to check the separation of UDPG from hexose esters and free sugars. After adding alcohol to $50 \%$ concentration the samples were made acid to Congo red paper with nitric acid, and $0.1 \mathrm{ml}$. of $20 \%$ mercuric acetate was added. The precipitate was dissolved ir $1 \mathrm{ml}$. of $0.4 \mathrm{M}$ ammonium acétate, and alcohol and nitric acid were added as before followed by 1 drop of mercuric acetate. After repeating the procedure two times more, the precipitate was suspended in water, decomposed with $\mathrm{H}_{2} \mathrm{~S}$, and heated at $\mathrm{pH} 2$ at $100^{\circ}$ for 15 mins. The solution was then neutralized with barium hydroxide and centrifuged. The supernotant was then concentrated and chromatographed. Glucose and galactose were found to be present in the incubated sample while the control contained only glucose.

(b) Chromatography with Acid-Ethanol

One ml. of UDPG solution containing $15 \mu$ moles 
was mixed with $0.2 \mathrm{ml}$. of $S$. fragilis extract and incubated $30 \mathrm{~min}$. at $37^{\circ}$. Proteins were then precipitated by adding $3 \mathrm{ml}$, of alcohol and a drop of $5 \%$ acetic acid. After centrifugation the alcoholic solution was concentrated and deposited as a band on a $15-\mathrm{cm}$. wide Whatman No. 1 paper. Spots with glucose and glucose 1-phosphate were run at the same time. The solvent used was made by mixing $75 \mathrm{ml}$. of ethanol with $30 \mathrm{ml}$. of $1 M$ sodium acetate buffer of $\mathrm{pH}$ 3.8. After chromatography a portion of the paper was sprayed with aniline-phthalate reagent (6) and heated: the $R_{\mathrm{f}}$ values were: $U D P G=0.18$, glucose 1-phosphate $=0.33$, glucose $=0.55$. From other experiments it was known that all the hexose monophosphates give about the same $R F$ with this solvent. Bands corresponding to the position of UDPG and of glucose phosphate were cut and extracted with water. The solutions were acidified to $\mathrm{pH} 2$ with sulfuric acid and heated $30 \mathrm{~min}$. at 1009 . Barium car bonate was then added to neutrality and the liquids were chromatographed with the pyridine-ethyl acetate solvent. The extract from the UDPG zone was found to contain both glucose and galactose. That of the hexose phosphate zone gave traces of glucose only.

\section{(c) Separation of the Cyclic Phosphates}

Experiment $I$. The experimental technique used was the same as in the previous experiment except that the solvent for the chromatography was made by mixing $75 \mathrm{ml}$. of $95 \%$ ethanol with $30 \mathrm{ml}$. of concentrated ammonia. The $R \mathbf{r}$ values were: glucose 1phosphate, 0.27; cyclic phosphate, 0.56 , and glucose, 0.61 . The glucose 1-phosphate, and the cyclic phosphate band were extracted hydrolyzed $20 \mathrm{~min}$. at $100^{\circ}$ in $1 \mathrm{~N}$ sulfuric ac d, the acid neutralized with barium hydroxide, and the supernatant was chromatographed with pyridine-ethyl tacetate. The extract from the diester zone was found to contain glucose and galactose, and that of the glucose 1-phosphate zone showed faint traces of glucose only.

Experiment II. In order to obtain a better sepa ration of hexoses from the diesters a similar experiment was carried out in which the ethanol-am monia solvent was allowed to run only $16 \mathrm{~cm}$., and after drying was replaced by pyridine-ethyl acetate. On "develoyment with aniline-phosphate, three bands were visible at $7.1,17.7$, and $30.2 \mathrm{~cm}$. A control with the enzymatic reaction stopped at 0-time showed the same bands. Known samples of glucose appeared a $31.7 \mathrm{~cm}$.; galactose, 29,5 cm.; glucose 1-phosphate and galactose 1-phosphate, $5-10 \mathrm{~cm}$. The bands $(4 \mathrm{~cm}$.) were extracted and hydrolyzed in order to identify the sugars as in the previous experiments.

All the samples showed the presence of glucose while galactose was found only in the hexose phosphate $(7.1 \mathrm{~cm}$.) and in the cyclic phosphate $(17.7$ $\mathrm{cm}$.) zones of the incubated sample.

\section{SUMMARY}

Treatment of uridine diphosphate glucose (UDPG) with an enzyme of S. fragilis was found to produce about $25 \%$ of a galactosecontaining compound. This compound is precipitated with mercuric ions like UDPG, and its migration in chromatography in acidethanol is similar. By alkaline treatment it gives, like UDPG, a doubly esterified hexose monophosphate. It is concluded that the compound is uridine diphosphate galactose, and the bearing of this finding on the mechanism of action of UDPG is discussed.

\section{REFERENCFS}

1. C.aputo; R., Leloir; E. F., Cardini, C. E., And 'Paladini, A. C., J. Biol. Chem. 184, 333, (1950); Cardini, G. E., Paladini, A. G., Caputo, R., and LELOIR, L. F., Nature 165, 191 (1950).

2. Jermy, M. A., AND Isherwood, F. A., Biochem. J. 44, 402 (1949).
3. Paladini, A. C., unpublished.

4. Forrest, H. S,, AND Todd, A. R., J. Chem. Soc. $1950,3295$.

5. Miettinen, J. K., And Virtanen, A. I., Acta Chem Scand. 3, 459 (1949)

6. Partridge, S. M., Nature 164, 443 (1949). 